\title{
Postinduction Requirement of NMDA Receptor Activation for Late-Phase Long-Term Potentiation of Developing Retinotectal Synapses In Vivo
}

\author{
Li-qin Gong, ${ }^{1}$ Ling-jie He, ${ }^{1}$ Zhi-yuan Dong, ${ }^{1}$ Xiao-hui Lu, ${ }^{1}$ Mu-ming Poo, ${ }^{1,2}$ and Xiao-hui Zhang ${ }^{1}$ \\ ${ }^{1}$ Institute of Neuroscience and State Key Laboratory of Neuroscience, Shanghai Institutes for Biological Sciences, Chinese Academy of Science, Shanghai \\ 200031, China, and 2Division of Neurobiology, Department of Molecular and Cell Biology, Helen Wills Neuroscience Institute, University of California, \\ Berkeley, Berkeley, California 94720-3200
}

\begin{abstract}
Spaced patterns of repetitive synaptic activation often result in a long-lasting, protein synthesis-dependent potentiation of synaptic transmission, known as late-phase long-term potentiation (L-LTP) that may serve as a substrate for long-term memory. Behavioral studies showed that posttraining blockade of NMDA subtype of the glutamate receptor (NMDAR) impaired long-term memory, although NMDAR activation is generally known to be required during LTP induction. In this study, we found that the establishment of L-LTP in vivo requires NMDAR activation within a critical time window after LTP induction. In the developing visual system of Xenopus laevis tadpole, L-LTP of retinotectal synapses could be induced by three episodes of theta burst stimulation (TBS) of the optic nerve with $5 \mathrm{~min}$ spacing ("spaced TBS"), but not by three TBS episodes applied en masse or spaced with intervals $\geq 10 \mathrm{~min}$. Within a time window of $\sim 30$ min after the spaced TBS, local perfusion of the tectum with NMDAR antagonist D-AP5 or $\mathrm{Ca}^{2+}$-chelator EGTA-AM impaired the establishment of L-LTP, indicating the requirement of postinduction activation of NMDAR/Ca ${ }^{2+}$ signaling. Moreover, inhibiting spontaneous spiking activity in the tectum by local application of tetrodotoxin (TTX) prevented L-LTP when TTX was applied for 15 min immediately after the spaced TBS but not $1 \mathrm{~h}$ later, whereas the same postinduction TTX application in the retina had no effect. These findings offer new insights into the synaptic basis for the requirement of postlearning activation of NMDARs and point to the importance of postlearning spontaneous circuit activity in memory formation.
\end{abstract}

\section{Introduction}

Persistent activity-induced long-term synaptic modification is generally regarded as the cellular basis for the developmental refinement of neural circuits and for learning and memory functions (Bliss and Collingridge, 1993; Katz and Shatz, 1996; Martin et al., 2000; Kandel, 2001). Based on the dependence of gene transcription and protein translation, long-term potentiation (LTP) can be divided into two phases-early-phase LTP (E-LTP) (lasting 1-2 h) and late-phase LTP (L-LTP) (lasting $>3 \mathrm{~h}$ ) (Huang et al., 1996; Kelleher et al., 2004b). The L-LTP is usually induced by spaced patterns of repetitive neuronal activity and more likely to serve as a cellular substrate for long-term memory (Bliss and Collingridge, 1993; Martin et al., 2000; Kandel, 2001; Pastalkova et al., 2006). It is well known that activation of NMDA-subtype glutamate receptors (NMDARs) by persistent synaptic activity is required for the induction of LTP (Bliss and Collingridge, 1993; Malenka and Nicoll, 1999). However, behavioral studies have shown that posttraining blockade of NMDARs

Received Nov. 11, 2010; revised Dec. 21, 2010; accepted Dec. 29, 2010.

This work was supported by National Basic Research Program of China Grant 2011CBA00400 (X.-h.Z.) and Knowledge Innovation Program of Chinese Academy of Sciences Grant KSCX2-YW-R-29 (X.-h.Z.). M.-m.P. was supported in part by National Institutes of Health Grant EY 014979.

Correspondence should be addressed to either of the following: Mu-ming Poo at the above address, E-mail: mpoo@berkeley.edu; or Xiao-hui Zhang at the above address, E-mail: xhzhang@ion.ac.cn.

DOI:10.1523/JNEUROSCI.5936-10.2011

Copyright $\odot 2011$ the authors $\quad 0270-6474 / 11 / 313328-08 \$ 15.00 / 0$ also impaired long-term associative memory (Martin et al., 2000; Shimizu et al., 2000; Kandel, 2001) and the map stability of hippocampal place cells (Kentros et al., 1998; Nakazawa et al., 2004). The synaptic basis for the posttraining requirement of NMDARs in long-term memory formation remains unclear. A possible scenario is that posttraining activation of NMDARs is essential for the establishment of L-LTP at activated synapses. In this study, we examined this issue in the developing Xenopus retinotectal synapse system in vivo.

Repetitive visual stimulation of the retina (Zhang et al., 2000; Engert et al., 2002; Lien et al., 2006; Dunfield and Haas, 2009) or electrical stimulation of the optic nerve (Zhang et al., 1998; Tao et al., 2001; Zhou et al., 2003; Pratt et al., 2008) rapidly induced long-term modifications of developing Xenopus retinotectal synapses as well as intratectal recurrent synapses. In the presence of burst spiking of tectal cells, stable LTP of developing retinotectal synapses could only be generated by appropriately spaced pattern of theta burst stimulation (TBS) in vivo (Zhou et al., 2003). However, the latter study used whole-cell recording to monitor synaptic efficacy in tectal cells for the duration of $<60 \mathrm{~min}$; thus, only E-LTP could be examined. In the present study, we used extracellular field potential recording in the optic tectum to monitor the synaptic efficacy for up to $4 \mathrm{~h}$ and found that L-LTP of these developing synapses could be induced by three episodes of TBS of the optic nerve that were spaced by 5 min intervals ("spaced TBS"), but not by that applied en masse. Surprisingly, 
we found that NMDAR activation is required not only during induction but also within a 30 min window after the induction for the establishment of L-LTP. Additional studies suggest that spontaneous spiking activity and cytoplasmic $\mathrm{Ca}^{2+}$ elevation in the tectal cell within the same postinduction time window are also required for the establishment of L-LTP. Together, our results suggest a synaptic basis for the phenomenon of postlearning requirement of NMDAR activation that were found in behavioral studies of long-term memory.

\section{Materials and Methods}

Tadpole preparation. Xenopus laevis tadpoles of stage 43-46 (Nieuwkoop and Faber, 1994) were prepared for the electrophysiological recording, as described previously (Zhang et al., 1998; Zhou et al., 2003). In brief, tadpoles were anesthetized with HEPES-buffered Ringer's solution containing $0.02 \%$ MS222 (3-aminobenzoic acid ethyl ester) and secured by insect pins to a Sylgard-coated dish, and treated with $\alpha$-bungarotoxin (5 $\mu \mathrm{g} / \mathrm{ml}$ ) for $20 \mathrm{~min}$ before the recording. For recording, the tadpole brain was split open along the midline to expose the inner surface of the tectum on one side, and the lens of the contralateral eye was removed to expose the optic disc for electric stimulation of the optic nerve. The Ringer's solution contained the following (in mM): $125 \mathrm{NaCl}, 2 \mathrm{KCl}, 2.5 \mathrm{CaCl}_{2}, 1.5$ $\mathrm{MgCl}_{2}, 10$ glucose, and 10 HEPES, $\mathrm{pH}$ 7.4. The care and use of Xenopus laevis followed the Animal Use Guideline of Shanghai Institutes for Biological Sciences, Chinese Academy of Sciences.

Electrophysiology. Electric stimulation of the optic nerve was made by a theta electrode (Sutter Instrument) filled with the Ringer's solution, and these test stimuli (pulse width, $0.1 \mathrm{~ms}$ ) were delivered at a frequency of 0.033 or $0.017 \mathrm{~Hz}$. To examine the long-term (up to $4 \mathrm{~h}$ ) change of the efficacy of retinotectal synapses, extracellular recording of monosynaptic field EPSPs (fEPSPs) was made with a glass microelectrode filled with the Ringer's solution (resistance of 5-6 M $\Omega$ ), which was placed in the caudal region of the contralateral optic tectum at a depth $40-60 \mu \mathrm{m}$ from the inner surface. The fEPSP signals were amplified with a microelectrode amplifier (MultiClamp 700A; Molecular Devices). The synaptic strength was quantified by measuring the initial slope of evoked fEPSPs $(20-80 \%$ of the rising phase), and the test-stimulus intensity was set to give a baseline fEPSP slope of $\sim 30-50 \%$ of the maximal amplitude that could be elicited by increasing the stimulus intensity in each tadpole experiment. Changes in synaptic strength with time were shown by plotting the average fEPSP slope over $5 \mathrm{~min}$ bins. In the experiments in which evoked EPSCs and spontaneous spiking activities were examined, whole-cell recording (with amphotericin B perforation) from the tectal cell or the retinal ganglion cell (RGC) was performed as described previously (Zhang et al., 2000), and the measurement of AMPAR- and NMDARmediated components of evoked EPSCs in tectal cells (at $V_{\text {clamp }}=+50$ $\mathrm{mV}$ ) followed the method as described by Wu et al. (1996), in the presence of $\mathrm{GABA}_{\mathrm{A}}$ receptor antagonist picrotoxin $(100 \mu \mathrm{M})$. Recorded signals were filtered (fEPSP: low pass, 2 or $0.5 \mathrm{kHz}$; high pass, $1 \mathrm{~Hz}$; spike and evoked EPSC: low pass, $5 \mathrm{kHz}$ ), digitalized (Digidata 1322A; Molecular Devices), and acquired at $10 \mathrm{kHz}$ by a computer with pCLAMP 9.2 (Molecular Devices). All recordings were done at room temperature $\left(22-24^{\circ} \mathrm{C}\right)$.

Single episode or three episodes of TBS to the optic nerve were used for the induction of E-LTP and L-LTP, respectively. Each episode of TBS consisted of five trains of stimuli (at $5 \mathrm{~s}$ interval), with each train composed of 10 bursts (five pulses at $100 \mathrm{~Hz}$ in each burst) at an interburst interval of $200 \mathrm{~ms}$. Before the LTP induction, a stable baseline of the fEPSP slope was observed for at least $30 \mathrm{~min}$, and postinduction fEPSP slopes were normalized by the baseline value.

Local drug perfusion. Local perfusion of the tectum or the retina was performed with a quartz capillary (inner diameter, $100 \mu \mathrm{m}$ ) placed at $\sim 200 \mu \mathrm{m}$ away from the recording site, in the presence of a continuous bath perfusion $(\sim 2 \mathrm{ml} / \mathrm{min})$. The flow rate of local perfusion was electrically control by an ALA Voltage Command Valve System (ALA Scientific Instruments). All chemicals were from Sigma-Aldrich, except that TTX was from the Institute of Hydrobiology (Wuhan, China).

Data analysis. The nonparametric Kolmogorov-Smirnov test and paired $t$ test were used for comparison of data between different groups or between E-LTP and L-LTP of the same group. The decay kinetics of the averaged fEPSP slope was fitted by a single-exponential function for a period from the maximal value of fEPSP slope to the end of recording, and the resultant decay time constant $\left(\tau_{\text {decay }}\right)$ was used as the parameter for estimating the LTP decay. Summary data were presented as mean \pm SEM unless stated otherwise.

\section{Results}

\section{Induction of L-LTP of developing retinotectal synapses}

To investigate L-LTP of retinotectal synapses, we monitored monosynaptic fEPSPs in the optic tectum of developing Xenopus tadpoles in response to extracellular stimulation of the optic nerve. Different components of the recorded field potentials were observed, including the presynaptic afferent volleys (Vanegas et al., 1971; Debski and Constantine-Paton, 1990) and the fEPSP, which were identified by using selective pharmacological blockersthe fEPSP was selectively abolished by locally applied antagonist 1,2, 3,4-tetrahydro-6-nitro-2,3-dioxo-benzo[f]quinoxaline-7-sulfonamide hydrate (NBQX) $(10 \mu \mathrm{M})$ against the AMPA subtype of the glutamate receptor (AMPAR), whereas both the presynaptic afferent volleys and the fEPSP were abolished by the $\mathrm{Na}^{+}$channel blocker tetrodotoxin (TTX) $(0.1 \mu \mathrm{M})$ (Fig. 1A). The initial slope of AMPAR-mediated fEPSPs $(20-80 \%$ of rising phase) was used to represent the efficacy of retinotectal glutamatergic synapses, and was stable for at least $4 \mathrm{~h}$ when the optic nerve was stimulated at an interval of $30 \mathrm{~s}$ or $1 \mathrm{~min}$, with electric pulses ( $0.1 \mathrm{~ms}$ width) at the intensity that elicited fEPSP slopes equal to $30-50 \%$ of the maximal evoked response (Fig. $1 B, C$ ).

Application of a single TBS to the optic nerve resulted in an increase in the slope of fEPSPs within $30 \mathrm{~min}$, indicating enhanced synaptic efficacy (Fig. $1 D, E$ ). This enhanced efficacy then gradually decayed to the baseline within $\sim 2 \mathrm{~h}\left(\tau_{\text {decay }}=106 \mathrm{~min}\right)$, consistent with the induction of E-LTP of retinotectal synapses observed by whole-cell recording from these neurons (Tao et al., 2001; Zhou et al., 2003). When three episodes of TBS were applied at a 5 min interval, we observed synaptic potentiation that lasted for $>3 \mathrm{~h}$, showing no detectable decay (Fig. $1 F, G$ ), indicating the induction of L-LTP. This L-LTP was further confirmed by its dependence on gene transcription and protein synthesis. In agreement with L-LTP induction in rodent hippocampal slices (Huang et al., 1996; Kelleher et al., 2004a), LTP at retinotectal synapses failed to be maintained beyond $2 \mathrm{~h}$ when the protein synthesis inhibitor anisomycin $(25 \mu \mathrm{M})$ or the gene transcription inhibitor actinomycin-D $(25 \mu \mathrm{M})$ was added in the bath solution for $30 \mathrm{~min}$, beginning at $10 \mathrm{~min}$ before the spaced TBS at $5 \mathrm{~min}$ intervals (Fig. $2 A, B)\left(\tau_{\text {decay }}, 63\right.$ and $92 \mathrm{~min}$, respectively). These results suggest that temporally spaced patterns of TBS to the optic nerve is capable of eliciting protein synthesis-dependent L-LTP of retinotectal synapses, similar to the induction of hippocampal L-LTP in vitro (Huang et al., 1996; Nguyen and Kandel, 1997; Kandel, 2001; Kelleher et al., 2004b).

\section{Effective TBS spacing for inducing stable L-LTP}

We further examined how the spacing of multiple TBS episodes influences the induction of L-LTP at developing Xenopus retinotectal synapses. We found that three TBS episodes applied en masse only induced an E-LTP that decayed to the baseline within $\sim 2 \mathrm{~h}$, with a $\tau_{\text {decay }}$ of $95 \mathrm{~min}$ (Fig. $3 \mathrm{~A}$ ). Compared with that found for three TBS spaced by 5 min intervals (Fig. 1G), the magnitude of L-LTP (defined by the mean fEPSP slope at 2.5-3 h after induction) showed progressive reduction when the interval was decreased to $2.5 \mathrm{~min}\left(\tau_{\text {decay }}=84 \mathrm{~min}\right.$ ) (Fig. $3 \mathrm{~B}$ ) or extended to 10 or $15 \mathrm{~min}\left(\tau_{\text {decay }}=101\right.$ and $181 \mathrm{~min}$ for 10 and $15 \mathrm{~min}$ intervals, 
A
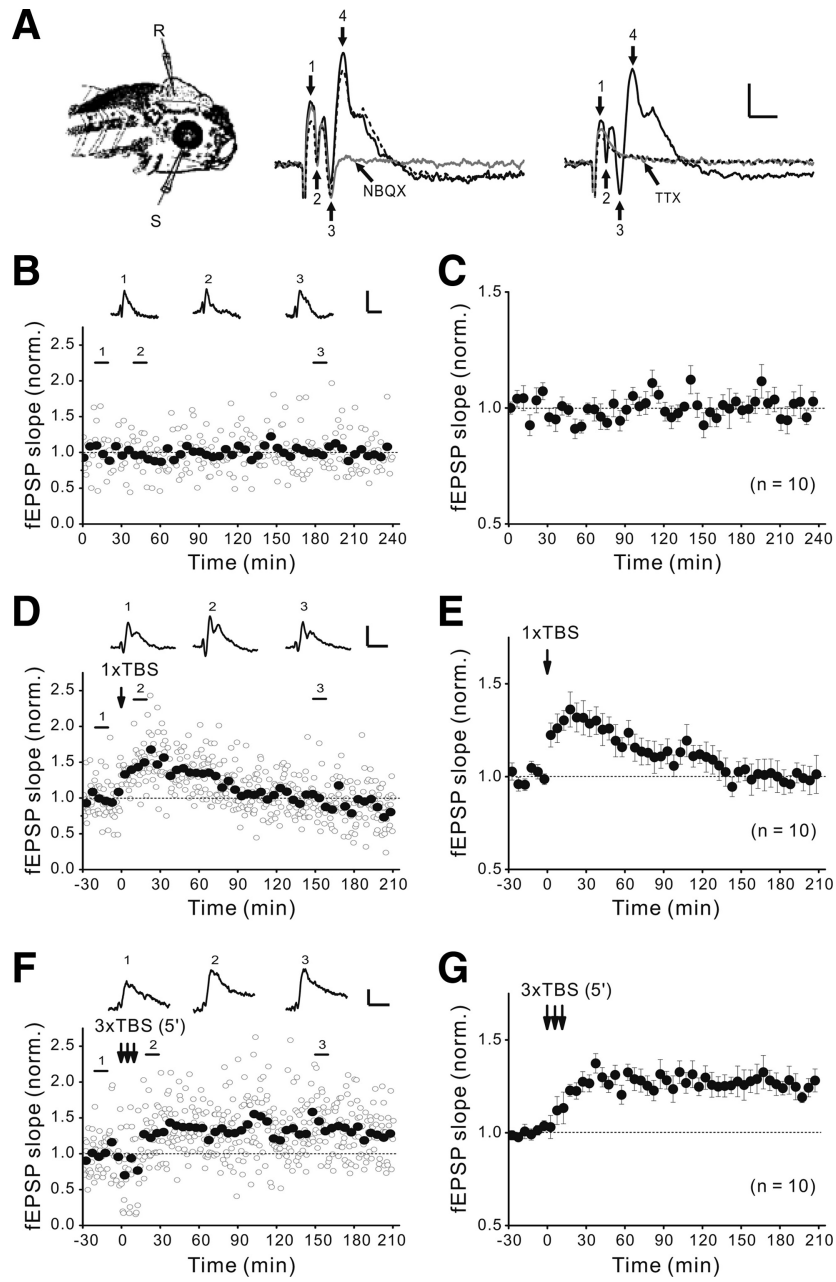

Figure 1. Induction of LTP by a single episode versus multiple episodes of TBS. A, Recording of field EPSPs in the optic tectum. Traces of the fEPSP elicited by electric stimulation of the optic nerve (" $S$ ") in the contralateral eye (current pulse width, $0.1 \mathrm{~ms}$ ). Middle, Black, Averaged fEPSP in normal Ringer's solution; dark gray, after perfusion with NBQX (10 $\mu \mathrm{M})$; dashed, after clearance of NBQX. Right, Black, Averaged fEPSP in Ringer's solution; dark gray, after perfusion with TTX $(0.1 \mu \mathrm{M})$; dashed, recorded when electrode was outside the tectum. The arrows mark various components of the field potential: stimulation artifact ("1"), presynaptic afferent volleys for fibers of different conduction velocities (" 2 " and " 3 "), and AMPAR-mediated fEPSP (" 4 "). Calibration: $0.05 \mathrm{mV}, 5 \mathrm{~ms}$. B, An example showing changes of fEPSP slopes (20 - 80\% of rising phase) over $4 \mathrm{~h}$, normalized by the mean value during the first $30 \mathrm{~min}$. Gray circles, Raw values of the fEPSP evoked by test stimuli at $30 \mathrm{~s}$ interval; filled circles, average over 5 min period. Traces above, Averaged trace of $20 \mathrm{fEPSPs}$ at the time marked by numbers. Calibration: $0.1 \mathrm{mV}$, $10 \mathrm{~ms}$. C, Summary of experiments shown in $\boldsymbol{B}$. $n$, Total number of experiments. $\boldsymbol{D}, \boldsymbol{E}$, Same as $\boldsymbol{B}$ and $\boldsymbol{C}$, except the application of a single episode of TBS at $0 \mathrm{~min}$ (arrow). $\boldsymbol{F}, \boldsymbol{G}$, Same as $\boldsymbol{B}$ and $\boldsymbol{C}$, except that three episodes of TBS (marked by arrows) were applied at 5 min intervals.

respectively) (Fig. 3C, $D, F, G$ ). However, similar amplitude of E-LTP was observed at 10-40 min after the spaced TBS with various intervals tested (Fig. 3G). Thus, $5 \mathrm{~min}$ is an effective interval of the spaced TBS for inducing stable L-LTP and was thus used as the standard spaced TBS for the rest of this study.

\section{Postinduction requirement of NMDAR activation in L-LTP}

Activation of NMDARs in the postsynaptic tectal cells during the induction is known to be required for E-LTP at these retinotectal synapses (Zhang et al., 1998, 2000; Zhou et al., 2003). We tested whether this is also true for L-LTP by using local perfusion of the tectum with NMDAR antagonist $\mathrm{D}(-)-2-$ amino-5-phosphonovaleric acid (D-AP5) $(100 \mu \mathrm{M})$ and found
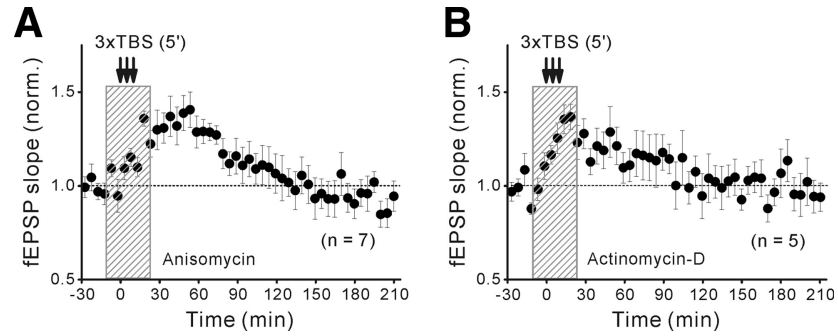

Figure 2. L-LTP requires protein synthesis and gene transcription. $A$, Summary results showing changes of fEPSP slopes before and after three episodes of TBS (spaced by $5 \mathrm{~min}$ ) when protein translation inhibitor anisomycin ( $25 \mu \mathrm{M}$ ) was applied to the bath solution for $40 \mathrm{~min}$ beginning at $10 \mathrm{~min}$ before the induction protocol (as indicated by the shadowed bar). The value of fEPSP slope represents the average over $5 \mathrm{~min}$ bins. The E-LTP was not affected (1.32 \pm $0.08 ; n=7)$, but L-LTP was abolished ( $0.96 \pm 0.06 ; p=0.009$ vs E-LTP, paired $t$ test). $\boldsymbol{B}$, Similar to $A$, except that the gene transcription inhibitor actinomycin $D(25 \mu \mathrm{M})$ was applied instead of anisomycin. Averaged amplitudes of E-LTP and L-LTP were $1.22 \pm 0.07$ and $1.00 \pm$ $0.09(n=5 ; p=0.05$, E-LTP vs L-LTP), respectively.

that the local perfusion of the tectum with D-AP5 for $30 \mathrm{~min}$, beginning at $10 \mathrm{~min}$ before the spaced TBS, prevented the development of both E-LTP and L-LTP (Fig. 4A), consistent with the requirement of NMDAR activation for LTP induction. Surprisingly, 15 min perfusion of D-AP5 immediately after the spaced TBS also prevented L-LTP without much effect on E-LTP (Fig. $4 B, E)$. This D-AP5 effect in blocking L-LTP was also found when it was applied at 15-30 min (Fig. 4C,E), but not at $45-60 \mathrm{~min}$, after the spaced TBS (Fig. 4D,E). As shown in Figure $4 E$, postinduction blockade of NMDARs did not affect the mean magnitude of E-LTP (defined as the average increment of the fEPSP slope during 10-40 $\mathrm{min}$ ) after three episodes of TBS spaced by various intervals. Interestingly, in contrast to the effect on L-LTP, $15 \mathrm{~min}$ application of D-AP5 immediately after a single episode of TBS had no apparent effect on the amplitude of E-LTP (Fig. $4 F$ ). Thus, NMDAR activation during the time window of $\sim 30 \mathrm{~min}$ after the spaced TBS is specifically required for inducing L-LTP.

\section{Postinduction requirement of $\mathrm{Ca}^{2+}$ signaling}

The critical role of $\mathrm{Ca}^{2+}$ influx through activated NMDARs is well established for activity-induced LTP in many brain areas (Bliss and Collingridge, 1993; Malenka and Nicoll, 1999). We thus further examined whether the effect of postinduction NMDAR activation on the L-LTP establishment is also dependent on the $\mathrm{Ca}^{2+}$ signal, by using $\mathrm{Ca}^{2+}$-chelators to buffer cytoplasmic $\mathrm{Ca}^{2+}$ at a low level. We found that local perfusion of the tectum with the membrane-permeable slow $\mathrm{Ca}^{2+}$-chelator EGTA-AM $(50 \mu \mathrm{M})$ for $30 \mathrm{~min}$ immediately after the spaced TBS prevented L-LTP without affecting E-LTP (Fig. $5 A$ ). This effect of EGTA is likely to be attributed to the buffering of postsynaptic rather than presynaptic $\mathrm{Ca}^{2+}$, because the EGTA-AM perfusion had no significant effect on the basal fEPSP slope over a $2 \mathrm{~h}$ period $(1.00 \pm 0.10 ; n=5)$. In contrast, similar perfusion of the tectum with the fast $\mathrm{Ca}^{2+}$-chelator BAPTA-AM (50 $\mu \mathrm{M}$; for $15 \mathrm{~min}$ ) gradually reduced fEPSPs to a level $\sim 55 \%$ of the original basal fEPSP within $60 \mathrm{~min}$ after the perfusion. Moreover, the same EGTA-AM perfusion at 60-90 min after the spaced TBS was much less effective in preventing L-LTP (Fig. $5 B$ ), consistent with the time window observed for the blocking effect of D-AP5 (Fig. 4E).

Roles of postinduction activation of L-type $\mathrm{Ca}^{2+}$ channels and $\mathrm{Ca}^{2+}$-permeable AMPARs

We further examined the potential role of $\mathrm{Ca}^{2+}$ influx through L-type voltage-gated $\mathrm{Ca}^{2+}$ channels (L-VGCCs) or $\mathrm{Ca}^{2+}$ - 
A
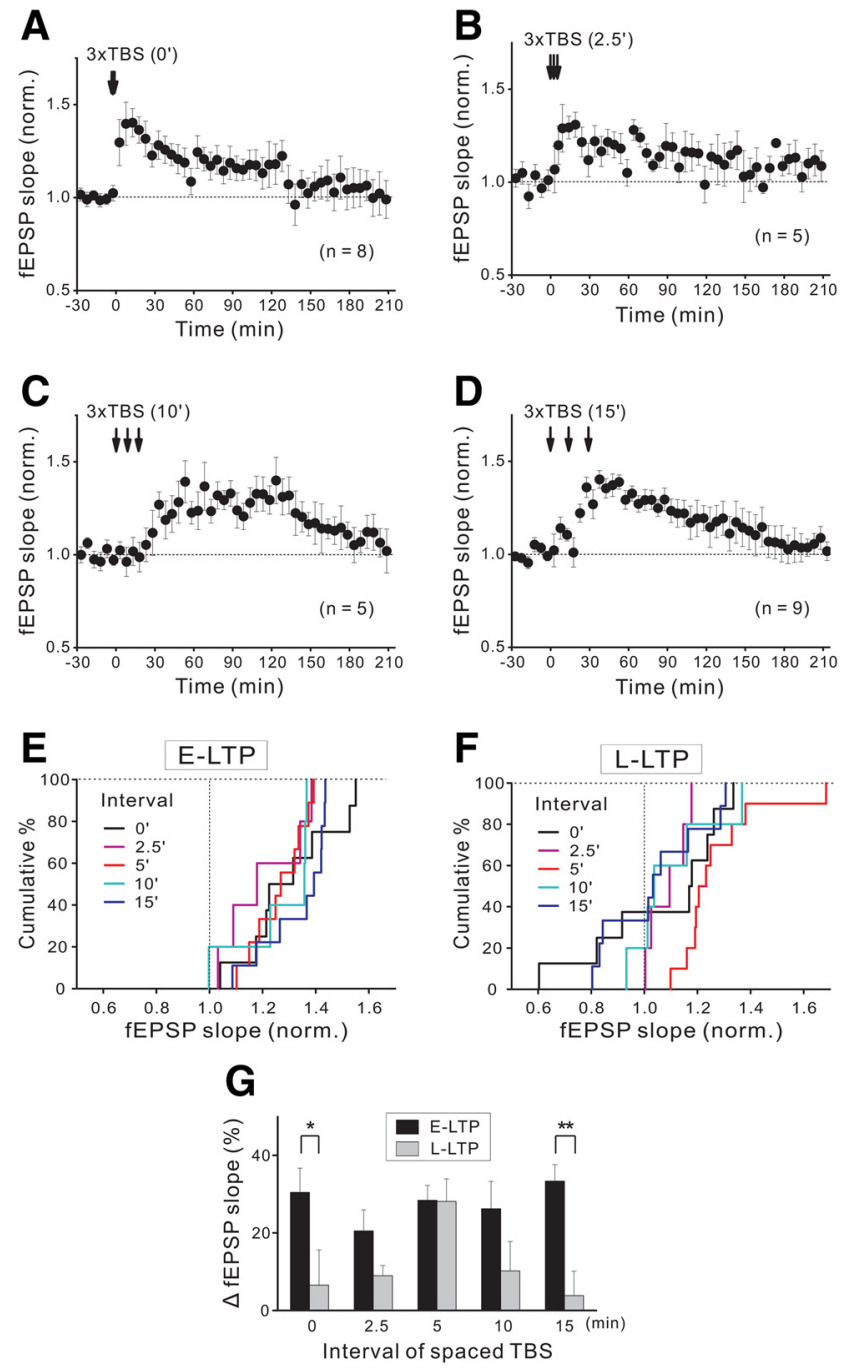

Figure 3. L-LTP stability depends on the interval of spaced TBS. A-D, Summary results showing changes of fEPSP slopes before and after that three episodes of TBS were applied en masse ( 5 s intervals) $(\boldsymbol{A})$, at $2.5 \mathrm{~min}(\boldsymbol{B}), 10 \mathrm{~min}(\boldsymbol{C})$, or $15 \mathrm{~min}(\boldsymbol{D})$ intervals. The value of fEPSP slope represents the average over 5 min bins. $\boldsymbol{E}, \boldsymbol{F}$, Cumulative distribution of the magnitude of E-LTP and L-LTP, defined by the average fEPSP slope at $10-40$ and $150-180$ min after the last TBS, respectively, induced by three episodes of TBS with different intervals. Significant difference was only found for L-LTP between the 5 and 15 min intervals ( $p=0.02$, KolmogorovSmirnov test). G, Average magnitude ( \pm SEM) of E-LTP and L-LTP induced by three episodes of TBS with the interval of $0,2.5,5,10$, or 15 min. ${ }^{*} p=0.03$; ${ }^{* *} p=0.01$; paired $t$ test.

permeable AMPARs (CP-AMPARs) during the postinduction period. First, we found that local perfusion of the tectum with the selective L-VGCC blocker nimodipine (for $30 \mathrm{~min}, 20 \mu \mathrm{M}$ ) immediately after the spaced TBS did not affect the establishment of L-LTP (Fig. 5C), suggesting that postinduction $\mathrm{Ca}^{2+}$ influx through L-VGCCs is not required. Second, consistent with the high-level expression of CP-AMPARs in a population of tectal neurons that are located primarily at caudo-medial region of the developing tectum (Aizenman et al., 2002), local perfusion of the tectum with the selective CP-AMPAR antagonist 1-trimethylammonio-5-[1-adamantanemethylammonio]pentane dibromide (IEM-1460) (100 $\mu \mathrm{M}$ in the perfusion pipette) (Magazanik et al., 1997) reduced the fEPSP slope by $\sim 20 \%$ (Fig. 6 A). Increasing the concentration of locally applied IEM-1460 from 100 to $300 \mu \mathrm{M}$ did not further reduced the evoked fEPSP slope (normalized fEPSP slopes, $0.85 \pm 0.05$ and $0.81 \pm 0.06$, respectively; $n=3$ ), indicating the IEM-1460 at $100 \mu \mathrm{M}$ could exert a maximal blocking effect on the
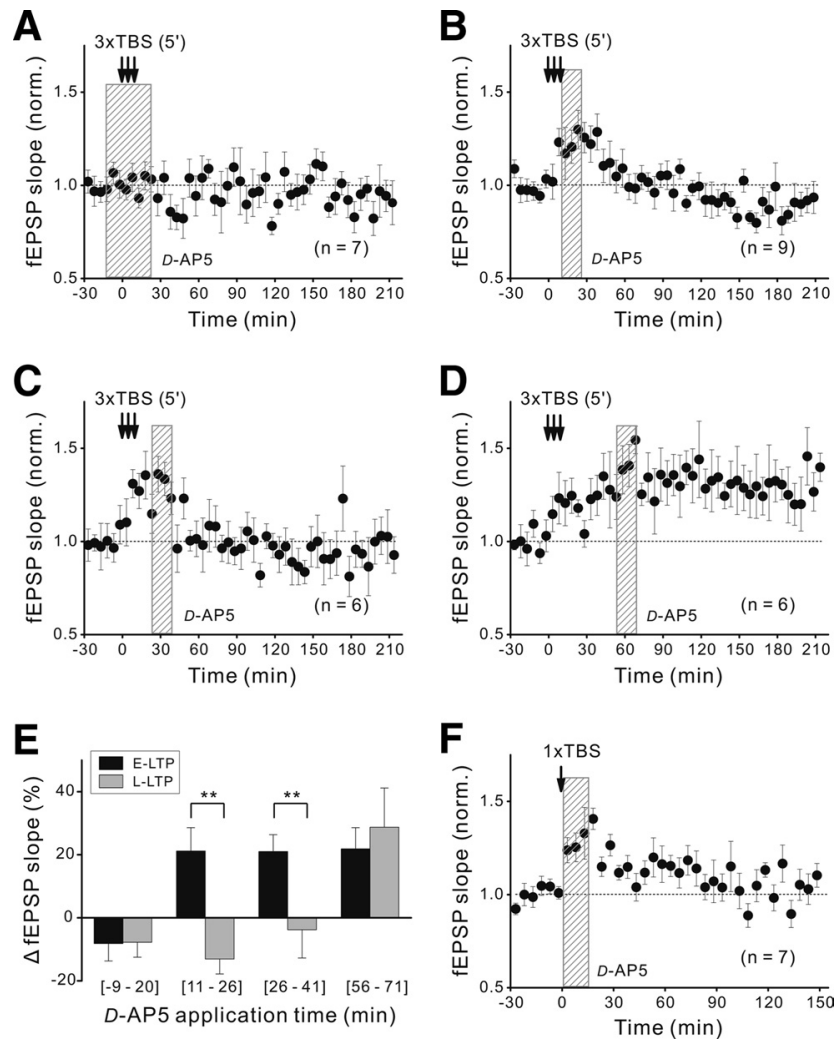

Figure 4. Postinduction NMDAR activation is required for L-LTP. A, Blockade of LTP induction by 30 min local perfusion of the tectum with D-AP5 ( $100 \mu \mathrm{m}$; marked by the shadow), beginning at 10 min before the spaced TBS (at 5 min interval). $\boldsymbol{B}-\boldsymbol{D}$, Effects of 15 min local perfusion of the tectum with D-AP5, beginning at 1,15, and 45 min after termination of the last episode of the spaced TBS, respectively. $\boldsymbol{E}$, Histograms depict the magnitude (mean \pm SEM) of E-LTP and L-LTP induced by the spaced TBS, under the condition of D-AP5 perfusion at different times. The same data set as in $\boldsymbol{A}-\boldsymbol{D}$. Significant difference is marked by a double asterisk $\left.{ }^{* *}\right)(p<0.01$, paired $t$ test). $\boldsymbol{F}$, Effect of 15 min perfusion of the tectum with D-AP5, beginning at 1 min after a single TBS.

CP-AMPAR-mediated transmission in the tectum. Moreover, such effect of IEM-1460 (at $100 \mu \mathrm{M}$ ) on basal fEPSPs could be completely washed out within $30 \mathrm{~min}$ after the cessation of drug perfusion (Fig. $6 B)$. We also noted that IEM-1460 at the concentration of $100 \mu \mathrm{M}$ also inhibits NMDARs to some extent $(0.78 \pm 0.05$ of the value before the drug application; $n=3$ ), as reported previously (Antonov and Johnson, 1996; Bolshakov et al., 2005), but far less than the effect of D-AP5. However, perfusion of the tectum with IEM-1460 at 100 $\mu \mathrm{M}$ (for $30 \mathrm{~min}$ ) immediately after the spaced TBS did not affect the development of L-LTP, although a transient reduction of the fEPSP slope was observed because of its effect on the basal fEPSP (Fig. 6C). Furthermore, we also tested another more potent and specific $\mathrm{CP}-$ AMPAR antagonist, 1-naphthyl acetyl spermine (NASPM) $\left(\mathrm{IC}_{50}=\right.$ $0.33 \mu \mathrm{M}$ ) (Koike et al., 1997). As shown in Figure 6, $D$ and $E$, local perfusion to the tectum with NASPM with increasing concentrations from 0.1 to $50 \mu \mathrm{M}$ showed a dose-dependent reduction of evoked fEPSP slopes. There was no difference in total blockade for 10 and $50 \mu \mathrm{M}$ NASPM $(0.77 \pm 0.03$ and $0.77 \pm 0.09, n=4$, respectively), but $50 \mu \mathrm{M}$ showed poor reversibility (Fig. $6 D, E$ ). This extent of maximal reduction is nearly the same as that caused by the perfusion with IEM-1460 (at $100 \mu \mathrm{M}$ ). Notably, we found that L-LTP still occurred under the postinduction blockade of CP-AMPARs with 50 $\mu \mathrm{M}$ NASPM (for $30 \mathrm{~min}$ after the spaced TBS) (Fig. $6 F$ ), although the fEPSP slope was maintained at a lowered level because the blocking effect of NASPM on the basal fEPSP was irreversible. 

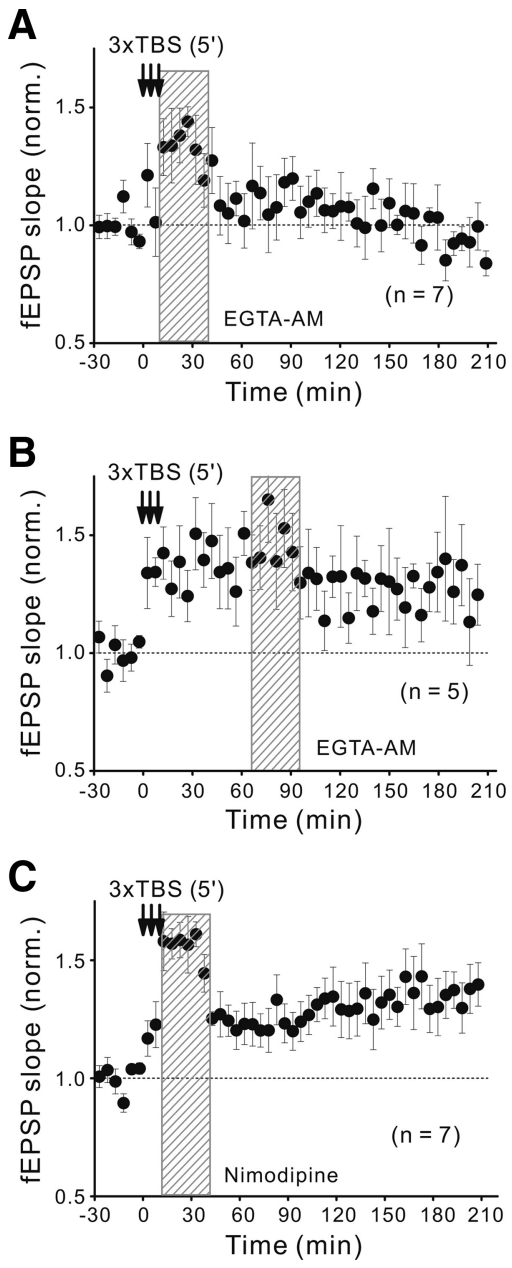

Figure 5. Requirement of postinduction $\mathrm{Ca}^{2+}$ elevation for L-LTP. $A, B$, Changes of fEPSP slope before and after the spaced TBS (with 5 min interval) when $30 \mathrm{~min}$ local perfusion of the tectum with EGTA-AM (50 $\mu \mathrm{M})$ immediately $(\boldsymbol{A})$ or $60 \mathrm{~min}(\boldsymbol{B})$ after the last episode of the spaced TBS. $\boldsymbol{C}$, Similar to $A$ except that the tectum was perfused locally for 30 min with the L-VGCC blocker nimodipine $(20 \mu \mathrm{m})$ immediately after the last episode of the spaced TBS.

Thus, these results of IEM-1460 and NASPM suggest that activation of CP-AMPARs in the first 30 min postinduction period is not required for the L-LTP development.

Together with the results of experiments using $\mathrm{Ca}^{2+}$. chelators, these results suggest that the effect of postinduction activation of NMDARs is most likely mediated by cytoplasmic $\mathrm{Ca}^{2+}$ elevation.

Importance of postinduction spontaneous spiking activity Postinduction NMDAR activation may be caused by the spontaneous spiking activity of tectal cells in vivo (Zhou et al., 2003; Tao and Poo, 2005) or the low-frequency $(0.017 \mathrm{~Hz})$ test stimulation used for measuring the efficacy of these synapses. Indeed, lowfrequency test pulses used in the hippocampal LTP experiments have been shown to increase the dependence of L-LTP on the protein synthesis (Fonseca et al., 2006) and induce transient incorporation of CP-AMPARs at postsynaptic sites associated with LTP induction (Plant et al., 2006). However, such effect of the test stimuli on L-LTP was excluded in the present study, because we found that stopping test stimulation for $45 \mathrm{~min}$ after the spaced TBS had no effect on the establishment of L-LTP (Fig. 7A). Furthermore, in the absence of test stimulation, local perfusion of the
A

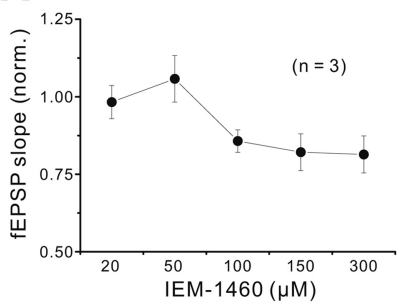

B

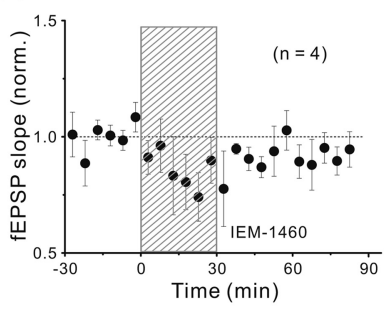

\section{C}

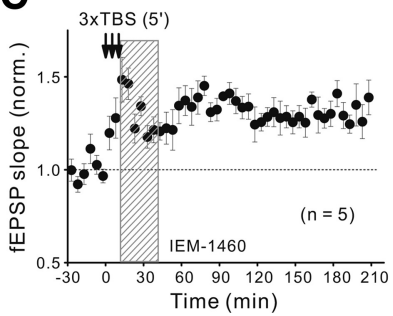

D

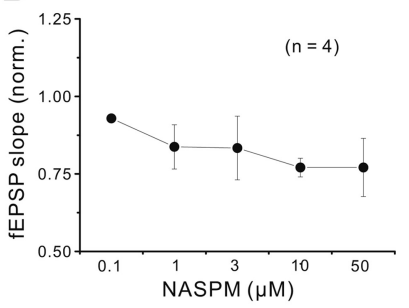

E

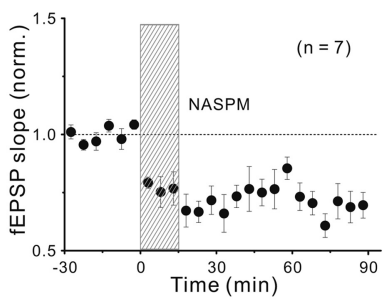

$\mathbf{F}$

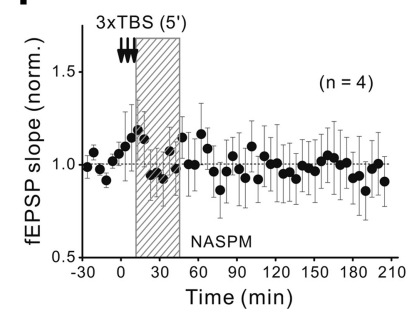

Figure 6. Postinduction activation of CP-AMPARs is not required for L-LTP. A, Dosedependent effect of a selective CP-AMPAR antagonist IEM-1460 in reducing the fEPSP slope. The fEPSP slopes were normalized by the average slope value before the drug application (by local perfusion to the tectum for $15 \mathrm{~min}$ ). $\boldsymbol{B}$, Reversibility of IEM-1460 effect on the basal fEPSP slopes. The shadowed bar indicates the duration of local perfusion of IEM-1480 (100 $\mu \mathrm{M}) . C$, Changes of fEPSP slope before and after the spaced TBS (with 5 min interval) when 30 min local perfusion of the tectum with IEM-1460 $(100 \mu \mathrm{M})$ immediately after the last episode of the spaced TBS. D-F, Same set of experiments as A-C except for another specific (P-AMPAR antagonist NASPM was used. The concentration of NASPM in $\boldsymbol{E}$ and $\boldsymbol{F}$ was at $50 \mu \mathrm{m}$.

A

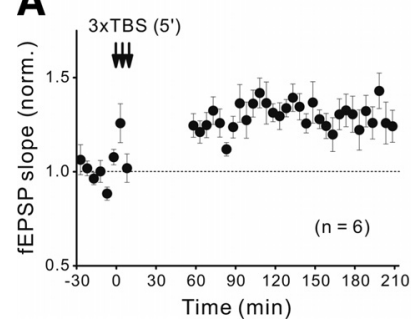

B

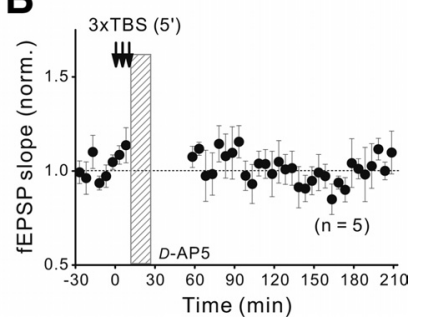

Figure 7. L-LTP stability is unaffected by postinduction test stimulation. $A$, Changes of fEPSP slope before and after three episodes of TBS (spaced with 5 min interval), in the absence of low-frequency test stimulation for $45 \mathrm{~min}$ after the last episode of TBS. Averaged amplitude of L-LTP (at 160-190 min after the last episode of TBS) was $1.28 \pm 0.08$ ( $n=6$; mean \pm SEM). $B$, Similar experiments as shown in $\boldsymbol{A}$ except that the tectum was perfused locally for $15 \mathrm{~min}$ with D-AP5 immediately after the last TBS episode. Averaged magnitude of L-LTP, $0.95 \pm 0.06$ $(n=5)$.

tectum with D-AP5 for 15 min immediately after the spaced TBS remained effective in blocking L-LTP (Fig. 7B).

To further test the role of spontaneous spiking activity, we locally perfused the tectum with a low concentration of TTX (25 $\mathrm{nM}$ ) for $15 \mathrm{~min}$ and found that the treatment quickly abolished action potentials in the tectum, as indicated by the abolishment of fEPSPs during the local perfusion (Fig. $8 \mathrm{~A}$ ). The spiking activ- 
A
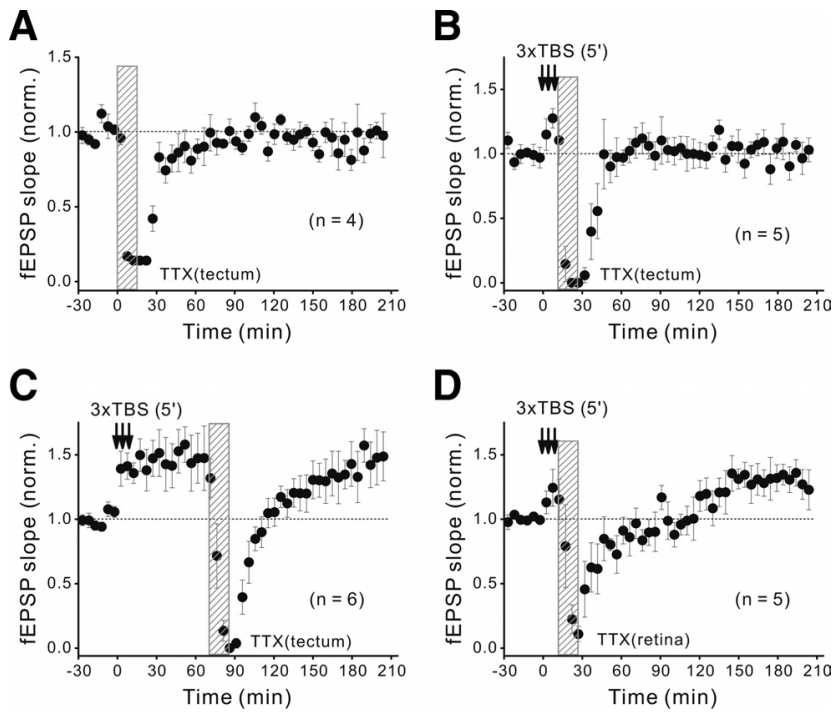

Figure 8. Postinduction spontaneous neuronal spiking in the tectum is required for L-LTP. $A-C$, Changes of the fEPSP slope before and after three episodes of TBS (spaced at $5 \mathrm{~min}$ ) when the tectum was locally perfused for $15 \mathrm{~min}$ with TTX ( $25 \mathrm{nM})$, in the absence of the spaced TBS $(\boldsymbol{A})$, and immediately $(\boldsymbol{B})$ or $60 \mathrm{~min}(\boldsymbol{C})$ after the last TBS of the spaced TBS. Shown is averaged magnitude of normalized fEPSP slope over 160-190 $\min . \boldsymbol{B}, 1.03 \pm 0.09$ ( $p=0.75$ vs the baseline, paired $t$ test). $\boldsymbol{C}, 1.45 \pm 0.18$ ( $p=0.96$ vs E-LTP). $\boldsymbol{D}$, Similar to $\boldsymbol{B}$ except that TTX (25 nm) was locally perfused to the retina. L-LTP magnitude, $1.30 \pm 0.11$ ( $p=0.05$ vs the baseline).

ity fully recovered after clearing TTX by perfusion with fresh Ringer's solution, as indicated by the gradual return of fEPSPs to the basal level (observed before TTX perfusion) within $60 \mathrm{~min}$ (Fig. 8 A). Importantly, such 15 min TTX perfusion of the tectum immediately after the spaced TBS was found to prevent the development of L-LTP (Fig. $8 \mathrm{~B}$ ) but had no effect on L-LTP when applied at $60 \mathrm{~min}$ after the spaced TBS (Fig. $8 C$ ). In contrast, we found that the 15 min TTX perfusion of the contralateral retina immediately after the spaced TBS did not affect the development of L-LTP (Fig. $8 D$ ), suggesting that spontaneous retina spiking activity during the first $15 \mathrm{~min}$ of postinduction period was not required for the development of L-LTP. Together, these results showed that spontaneous spiking activity in the tectum, rather than that in the retina, during the early postinduction period is essential for establishing L-LTP.

\section{Discussion}

In addition to the well known requirement of NMDAR activation during the induction of LTP (Bliss and Collingridge, 1993; Malenka and Nicoll, 1999), our in vivo study in developing Xenopus tectum demonstrates that the development of L-LTP but not E-LTP also requires NMDAR activation within a critical postinduction period of $\sim 30 \mathrm{~min}$. Our results further suggest that spontaneous spiking activities in the tectum may contribute to the activation of postinduction NMDAR/ $/ \mathrm{Ca}^{2+}$ signaling required for the establishment of L-LTP. This is analogous to the requirement of postlearning reactivation of NMDARs for the formation of long-term spatial memory and fear memory (Martin et al., 2000; Shimizu et al., 2000; Kandel, 2001; Nakazawa et al., 2004), further strengthening the notion that L-LTP is causally linked to long-term memory formation.

\section{L-LTP induction by spaced patterns of synaptic activation} Human and animal behavior studies have suggested that repeated training spaced with appropriate intervals is far more effective in inducing long-term memory than training without spacing, a phenomenon known as spacing effect (Ebbinghaus, 1885; Carew et al., 1972; Gerber et al., 1998; Beck et al., 2000; Sutton et al., 2002; Philips and Carew, 2009). In support of the notion that activity-induced LTP is the neural substrate for the formation of long-term memory, similar spacing effect was found for neural activity patterns that are effective for inducing persistent synaptic modifications. This has been shown for the induction of longterm facilitation of sensorimotor synapses in Aplysia (Montarolo et al., 1986; Mauelshagen et al., 1996; Martin et al., 1997; Kandel, 2001) and late-phase LTP in the rodent hippocampus (Frey et al., 1993; Nguyen et al., 1994; Huang et al., 1996; Huang and Kandel, 2005). The present study further demonstrates that at retinotectal synapses of Xenopus tadpoles, the spaced TBS is highly effective in inducing stable, protein synthesis-dependent L-LTP (up to $4 \mathrm{~h}$ ), whereas the same number of stimuli delivered en masse only induced E-LTP (Fig. 1). Our results also indicate that $5 \mathrm{~min}$ (but not $\geq 10 \mathrm{~min}$ ) is an effective interval of the spaced TBS for inducing stable L-LTP at these developing synapses (Fig. 3). Moreover, LTP induced by spaced TBS with 5 min interval did not show any significant decay within the recording period up to $4 \mathrm{~h}$ (Fig. $1 G$ ), whereas LTP induced by spaced TBS with other different intervals exhibited similar decay kinetics with the $\tau_{\text {decay }}$ in a range of 85-180 min. These results are consistent with the existence of a gradual transition for decaying LTP to a stable L-LTP. We also note that there are relatively big differences in the onset kinetics of LTP induced by the single episode or three episodes of TBS. We have standardized the stimulation intensity at a level that elicited a baseline fEPSP slope equal to $30-50 \%$ of the maximal value, yielding comparable E-LTP magnitudes in different experiments (Figs. 1, 3). Nevertheless, we observed considerable variation in the time course of E-LTP development after the same induction protocol among different tadpoles (data not shown), although the variability of the magnitudes of E-LTP was much less, when measured at 10-40 min after TBS.

Similar spaced training effect on the synaptic plasticity was also observed in Xenopus tadpoles exposed to visual training: The visual stimulus-induced spiking activity of tectal cells (as reflected by $\mathrm{Ca}^{2+}$ signals) was persistently elevated in a subpopulation of tectal cells after conditioning with visual stimulation spaced by 5 min interval, but not with visual stimulation without spacing (Dunfield and Haas, 2009). This elevated tectal spiking response could result directly from the L-LTP of retinotectal synapses induced by the spaced activation of these synapses shown here. The effective interval of spaced neural activities for inducing protein synthesis-dependent L-LTP varied from seconds to minutes in different systems (Nguyen et al., 1994; Huang et al., 1996; Mauelshagen et al., 1996; Frey and Morris, 1997; Kandel, 2001). Recent molecular studies on long-term memory formation in Aplysia and Drosophila have suggested that the optimal interval for the spaced learning may be regulated by Ras- or phosphatase SHP2-dependent activation of MAPK (mitogen-activated protein kinase) (Philips et al., 2007; Ye et al., 2008; Pagani et al., 2009). It would be of interest to examine whether and how these signaling pathways are involved in determining the optimal spacing of neural activity that induces L-LTP.

\section{Role of spontaneous spiking activity in E-LTP and L-LTP stabilization}

Previous studies have shown that activity-induced LTP is vulnerable to reversal by random/spontaneous spiking bursts (at frequencies of 6-8 Hz) of postsynaptic neurons after E-LTP induction in the hippocampus of free moving rats (Xu et al., 
1998). In Xenopus retinotectal system, whole-cell recording from tectal cells showed rapid decay of single TBS-induced E-LTP in tectal cells that exhibited frequent burst spiking activity $(\geq 5 \mathrm{~Hz})$, which occurred either spontaneously or on random visual inputs (Zhou et al., 2003). In the present study, we observed a more gradual decay of E-LTP induced by a single TBS (Fig. 1D,E), presumably because our fEPSP recording monitored heterogeneous populations of neurons exhibiting differential decay of E-LTP because of varying levels of spontaneous activity. However, previous evidence (Woo and Nguyen, 2003; Zhou et al., 2003) and our present results (Figs. $1 B$, 3) both suggest that the decay of E-LTP caused by spontaneous spiking could be completely overcome by LTP induction with properly spaced TBS. Interestingly, the role of spontaneous spiking activity after the spaced TBS is opposite to that after a single TBS-it helps to stabilize L-LTP instead of destabilizing E-LTP (Fig. 8). Additional studies of the differences in the pattern of spontaneous spiking after a single episode versus multiple spaced episodes of TBS may help to reveal the mechanism underlying the stabilization of L-LTP.

The present study also showed that spontaneous spiking activity in the tectum responsible for stabilizing L-LTP was not driven by RGCs, because inhibiting RGC spiking by locally applied TTX to the contralateral retina after the spaced TBS did not affect L-LTP (Fig. 8D). However, random visual stimuli (light flashes) were shown to induce a high level of tectal cell bursting and enhance the decay of E-LTP induced by a single episode of TBS (Zhou et al., 2003). Thus, spiking activity of tectal cells elicited by different inputs may play differential roles in regulating the stability of E-LTP and L-LTP. Interestingly, a recent study on this developing retinotectal system showed that spaced visual training at the interval of $5 \mathrm{~min}$ led to an increased postconditioning spontaneous correlated activity among tectal cells for $\sim 10 \mathrm{~min}$, accompanying the induction of long-lasting potentiation of tectal spiking responses on the flash light stimulation (Dunfield and Haas, 2009). The elevated spontaneous correlated activity among tectal cells activated by spaced stimulation may thus help to consolidate L-LTP during the early postinduction period.

\section{Physiological implications}

Behavioral studies showed that posttraining blockade of NMDARs selectively impaired long-term spatial memory and emotional memory in behaving rodents (Martin et al., 2000; Shimizu et al., 2000; Kandel, 2001; Nakazawa et al., 2004). These findings suggest that memory consolidation may require a postlearning, NMDAR-dependent reinforcement of synaptic changes. The time window sensitive to the NMDAR blockade was found to be $<2 \mathrm{~h}$ after the training (Packard and Teather, 1997a,b). Moreover, defects of long-term but not short-term memory was found when L-LTP was selectively disrupted in transgenic mice overexpressing a mutated form of the regulatory subunit of protein kinase A (Abel et al., 1997; Kandel, 2001), or in mice treated with the selective protein kinase $\mathrm{M} \zeta$ inhibitor ZIP ( $\zeta$-inhibitory peptide) (Pastalkova et al., 2006), suggesting that L-LTP may serve as neural substrate for long-term memory. Protein kinase A or $\mathrm{M} \zeta$ activity was also specifically elevated during the induction of L-LTP but not E-LTP, in response to the NMDAR/Ca ${ }^{2+}$ signal (Huang et al., 1996; Sacktor, 2008). By directly demonstrating the requirement of postinduction activation of NMDARs for L-LTP but not E-LTP, our results further strengthen the link between L-LTP and long-term memory and offer new insights into the synaptic basis for the requirement of postlearning activation of NMDARs observed in behavioral studies of long-term memory. Furthermore, our study underscores the importance of postlearning spontaneous neural activity in long-term synaptic modification and memory formation.

\section{Notes}

Supplemental material for this article is available at http://www.ion.ac. cn/admin_1/HXEditor/UploadFile/2011119151718991.pdf. The supplemental material consists of three supplemental figures, showing (1) the verification of spatial specificity and effectiveness of local effect of drugs applied in the tectum, as well as the normal development of L-LTP under the local perfusion with Ringer's solution (supplemental Fig. S1); (2) the effect of local perfusion with D-AP5 and CP-AMPAR antagonist IEM1460 on glutamate transmission of retinotectal synapses (supplemental Fig. S2); and (3) a 45\% reduction of basal fEPSPs caused by local perfusion of the tectum of the fast $\mathrm{Ca}^{2+}$-chelator BAPTA-AM but no reduction by the EGTA-AM perfusion over a $2 \mathrm{~h}$ period (supplemental Fig. S3). This material has not been peer reviewed.

\section{References}

Abel T, Nguyen PV, Barad M, Deuel TA, Kandel ER, Bourtchouladze R (1997) Genetic demonstration of a role for PKA in the late phase of LTP and in hippocampus-based long-term memory. Cell 88:615-626.

Aizenman CD, Muñoz-Elías G, Cline HT (2002) Visually driven modulation of glutamatergic synaptic transmission is mediated by the regulation of intracellular polyamines. Neuron 34:623-634.

Antonov SM, Johnson JW (1996) Voltage-dependent interaction of openchannel blocking molecules with gating of NMDA receptors in rat cortical neurons. J Physiol 493:425-445.

Beck CD, Schroeder B, Davis RL (2000) Learning performance of normal and mutant Drosophila after repeated conditioning trials with discrete stimuli. J Neurosci 20:2944-2953.

Bliss TV, Collingridge GL (1993) A synaptic model of memory: long-term potentiation in the hippocampus. Nature 361:31-39.

Bolshakov KV, Kim KH, Potapjeva NN, Gmiro VE, Tikhonov DB, Usherwood PN, Mellor IR, Magazanik LG (2005) Design of antagonists for NMDA and AMPA receptors. Neuropharmacology 49:144-155.

Carew TJ, Pinsker HM, Kandel ER (1972) Long-term habituation of a defensive withdrawal reflex in Aplysia. Science 175:451-454.

Debski EA, Constantine-Paton M (1990) Evoked pre-and post-synaptic activity in the optic tectum of the cannulated tadpole. J Comp Physiol A 167:377-390.

Dunfield D, Haas K (2009) Metaplasticity governs natural experiencedriven plasticity of nascent embryonic brain circuits. Neuron 64:240-250.

Ebbinghaus HE (1885) Memory: a contribution to experimental psychology. New York: Dover.

Engert F, Tao HW, Zhang LI, Poo MM (2002) Moving visual stimuli rapidly induce direction sensitivity of developing tectal neurons. Nature 419:470-475.

Fonseca R, Nägerl UV, Bonhoeffer T (2006) Neuronal activity determines the protein synthesis dependence of long-term potentiation. Nat Neurosci 9:478-480.

Frey U, Morris RG (1997) Synaptic tagging and long-term potentiation. Nature 385:533-536.

Frey U, Huang YY, Kandel ER (1993) Effects of cAMP simulate a late stage of LTP in hippocampal CA1 neurons. Science 260:1661-1664.

Gerber B, Wüstenberg D, Schütz A, Menzel R (1998) Temporal determinants of olfactory long-term retention in honeybee classical conditioning: nonmonotonous effects of the training trial interval. Neurobiol Learn Mem 69:71-78.

Huang YY, Kandel ER (2005) Theta frequency stimulation induces a local form of late phase LTP in the CA1 region of the hippocampus. Learn Mem 12:587-593.

Huang YY, Nguyen PV, Abel T, Kandel ER (1996) Long-lasting forms of synaptic potentiation in the mammalian hippocampus. Learn Mem 3:74-85.

Kandel ER (2001) The molecular biology of memory storage: a dialogue between genes and synapses. Science 294:1030-1038.

Katz LC, Shatz CJ (1996) Synaptic activity and the construction of cortical circuits. Science 274:1133-1138.

Kelleher RJ 3rd, Govindarajan A, Jung HY, Kang H, Tonegawa S (2004a) 
Translational control by MAPK signaling in long-term synaptic plasticity and memory. Cell 116:467-479.

Kelleher RJ 3rd, Govindarajan A, Tonegawa S (2004b) Translational regulatory mechanisms in persistent forms of synaptic plasticity. Neuron 44:59-73.

Kentros C, Hargreaves E, Hawkins RD, Kandel ER, Shapiro M, Muller RV (1998) Abolition of long-term stability of new hippocampal place cell maps by NMDA receptor blockade. Science 280:2121-2126.

Koike M, Iino M, Ozawa S (1997) Blocking effect of 1-naphthyl acetyl spermine on $\mathrm{Ca}^{2+}$-permeable AMPA receptors in cultured rat hippocampal neurons. Neurosci Res 29:27-36.

Lien CC, Mu Y, Vargas-Caballero M, Poo MM (2006) Visual stimuliinduced LTD of GABAergic synapses mediated by presynaptic NMDA receptors. Nat Neurosci 9:372-380.

Magazanik LG, Buldakova SL, Samoilova MV, Gmiro VE, Mellor IR, Usherwood PN (1997) Block of open channels of recombinant AMPA receptors and native AMPA/kainate receptors by adamantane derivatives. J Physiol 505:655-663.

Malenka RC, Nicoll RA (1999) Long-term potentiation-a decade of progress? Science 285:1870-1874.

Martin KC, Casadio A, Zhu H, Yaping E, Rose JC, Chen M, Bailey CH, Kandel ER (1997) Synapse-specific, long-term facilitation of Aplysia sensory to motor synapses: a function for local protein synthesis in memory storage. Cell 91:927-938.

Martin SJ, Grimwood PD, Morris RG (2000) Synaptic plasticity and memory: an evaluation of the hypothesis. Annu Rev Neurosci 23:649-711.

Mauelshagen J, Parker GR, Carew TJ (1996) Dynamics of induction and expression of long-term synaptic facilitation in Aplysia. J Neurosci 16:7099-7108.

Montarolo PG, Goelet P, Castellucci VF, Morgan J, Kandel ER, Schacher S (1986) A critical period for macromolecular synthesis in long-term heterosynaptic facilitation in Aplysia. Science 234:1249-1254.

Nakazawa K, McHugh TJ, Wilson MA, Tonegawa S (2004) NMDA receptors, place cells and hippocampal spatial memory. Nat Rev Neurosci 5:361-372.

Nguyen PV, Kandel ER (1997) Brief theta-burst stimulation induces a transcription-dependent late phase of LTP requiring cAMP in area CA1 of the mouse hippocampus. Learn Mem 4:230-243.

Nguyen PV, Abel T, Kandel ER (1994) Requirement of a critical period of transcription for induction of a late phase of LTP. Science 265:1104-1107.

Nieuwkoop PD, Faber J, eds (1994) Normal table of Xenopus laevis. New York: Garland Publishing.

Packard MG, Teather LA (1997a) Double dissociation of hippocampal and dorsal-striatal memory systems by posttraining intracerebral injections of 2-amino-5-phosphonopentanoic acid. Behav Neurosci 111:543-551.

Packard MG, Teather LA (1997b) Posttraining injections of MK-801 produce a time-dependent impairment of memory in two water maze tasks. Neurobiol Learn Mem 68:42-50.

Pagani MR, Oishi K, Gelb BD, Zhong Y (2009) The phosphatase SHP2 regulates the spacing effect for long-term memory induction. Cell 139: $186-198$.
Pastalkova E, Serrano P, Pinkhasova D, Wallace E, Fenton AA, Sacktor TC (2006) Storage of spatial information by the maintenance mechanism of LTP. Science 313:1141-1144.

Philips GT, Carew TJ (2009) It's all about timing. Cell 139:23-25.

Philips GT, Tzvetkova EI, Carew TJ (2007) Transient mitogen-activated protein kinase activation is confined to a narrow temporal window required for the induction of two-trial long-term memory in Aplysia. J Neurosci 27:13701-13705.

Plant K, Pelkey KA, Bortolotto ZA, Morita D, Terashima A, McBain CJ, Collingridge GL, Isaac JT (2006) Transient incorporation of native GluR2-lacking AMPA receptors during hippocampal long-term potentiation. Nat Neurosci 9:602-604.

Pratt KG, Dong W, Aizenman CD (2008) Development and spike timingdependent plasticity of recurrent excitation in the Xenopus optic tectum. Nat Neurosci 11:467-475.

Sacktor TC (2008) PKMzeta, LTP maintenance, and the dynamic molecular biology of memory storage. Prog Brain Res 169:27-40.

Shimizu E, Tang YP, Rampon C, Tsien JZ (2000) NMDA receptordependent synaptic reinforcement as a crucial process for memory consolidation. Science 290:1170-1174.

Sutton MA, Ide J, Masters SE, Carew TJ (2002) Interaction between amount and pattern of training in the induction of intermediate- and long-term memory for sensitization in Aplysia. Learn Mem 9:29-40.

Tao HW, Poo MM (2005) Activity-dependent matching of excitatory and inhibitory inputs during refinement of visual receptive fields. Neuron 45:829-836.

Tao HW, Zhang LI, Engert F, Poo M (2001) Emergence of input specificity of LTP during development of retinotectal connections in vivo. Neuron 31:569-580.

Vanegas H, Essayag-Millán E, Laufer M (1971) Response of the optic tectum to stimulation of the optic nerve in the teleost Eugerres plumieri. Brain Res 31:107-118.

Woo NH, Nguyen PV (2003) Protein synthesis is required for synaptic immunity to depotentiation. J Neurosci 23:1125-1132.

Wu G, Malinow R, Cline HT (1996) Maturation of a central glutamatergic synapse. Science 274:972-976.

Xu L, Anwyl R, Rowan MJ (1998) Spatial exploration induces a persistent reversal of long-term potentiation in rat hippocampus. Nature 394:891-894.

Ye X, Shobe JL, Sharma SK, Marina A, Carew TJ (2008) Small G proteins exhibit pattern sensitivity in MAPK activation during the induction of memory and synaptic facilitation in Aplysia. Proc Natl Acad Sci U S A 105:20511-20516.

Zhang LI, Tao HW, Holt CE, Harris WA, Poo M (1998) A critical window for cooperation and competition among developing retinotectal synapses. Nature 395:37-44.

Zhang LI, Tao HW, Poo M (2000) Visual input induces long-term potentiation of developing retinotectal synapses. Nat Neurosci 3:708-715.

Zhou Q, Tao HW, Poo MM (2003) Reversal and stabilization of synaptic modifications in a developing visual system. Science 300:1953-1957. 